\section{Micropropagation of Little Bluestem (Schizachyrium scoparium L.)}

\author{
Susan M. Hawkins and Carol D. Robacker ${ }^{1}$ \\ Department of Horticulture, University of Georgia, 1109 Experiment Street, \\ Griffin, GA 30223
}

Additional index words. little bluestem, native grasses, tissue culture

Abstract. Native grasses are increasingly used in the landscape. Little bluestem (Schizachyrium scoparium L.), a perennial bunchgrass native to most of the United States, has ornamental traits, such as variation in leaf color, differences in growth morphology, and attractive seed heads. Traditionally, cultivars of little bluestem are propagated by division, which limits the production of new plants. Our objective in this study was to develop an improved micropropagation protocol for little bluestem that would produce true-to-type plants. In 2016, we cultured immature inflorescences of eight genotypes of little bluestem on Murashige and Skoog (MS) medium with four combinations of kinetin $\left(1.0\right.$ or $\left.2.0 \mathrm{mg} \cdot \mathrm{L}^{-1}\right)$ and $2,4-\mathrm{D}\left(0.5\right.$ or $\left.1.0 \mathrm{mg} \cdot \mathrm{L}^{-1}\right)$ under three levels of light (dark, semilight, full light) to initiate callus. Cultures were evaluated 30 days after initiation and those that had initiated callus were subcultured. Media for subculturing and rooting contained either $0.1 \mathrm{mg} \cdot \mathrm{L}^{-1}$ or no 1-Naphthaleneacetic acid (NAA). Light level had no effect on callus initiation. Initiation media with $1.0 \mathrm{mg} \cdot \mathrm{L}^{-1}$ kinetin and either level of 2,4-D induced callus at almost twice the rate of media with 2.0 $\mathrm{mg} \cdot \mathrm{L}^{-1}$ kinetin, and cultures initiated on those media also produced almost twice the number of rooted plants over all genotypes. Genotype affected the number of rooted plants produced. The addition of NAA to medium for subculturing and rooting did not increase the number of rooted plants. In 2017, we cultured immature inflorescences of four genotypes of little bluestem on MS medium with $0.5 \mathrm{mg} \cdot \mathrm{L}^{-1} \mathbf{2 , 4 - D}$ and either 1.0 $\mathrm{mg} \cdot \mathrm{L}^{-1}$ kinetin or 6-benzylaminopurine (BAP) under full light. Cultures were evaluated 30 days after initiation. Cultures that had initiated callus were subcultured onto MS medium with the same growth regulators as the initiation medium but without 2,4-D. Cultures were cycled between subculture medium with growth regulator and subculture medium with no additional growth regulator until rooted. Cultures initiated and subcultured on medium with BAP initiated two to three times more callus than those on kinetin and produced twice as many rooted plants. Our recommendation for rapid micropropagation of little bluestem is to initiate cultures on MS medium with $1.0 \mathrm{mg} \cdot \mathrm{L}^{-1}$ BAP and $0.5 \mathrm{mg} \cdot \mathrm{L}^{-1}$ 2,4-D. After callus initiation, cultures should be subcultured to medium with BAP but no 2,4-D, alternating with medium with no additional growth regulators, until rooted.

Ornamental grasses are increasingly used in the landscape (Meyer, 2012). Sales of ornamental grasses in the United States were $\$ 158,061,021$ in 2014 , a substantial increase from $\$ 124,261,118$ in 2009 (U.S. Department of Agriculture, 2014). As well as being attractive, native ornamental grasses provide ecological functions, such as food and nesting areas for wildlife and support for pollinators (Fu et al., 2004; Tober and Jensen, 2013).

Little bluestem (Schizachyrium scoparium L.) is a perennial grass native to most of the continental United States (Fu et al., 2004; Springer, 2012; Williams and Briske, 1991). In recent years, it also has become a popular landscape plant (Fu et al., 2004; Meyer, 2012). Little bluestem has a wide range of adaptability to climate and soils and is drought tolerant (Meyer et al., 2017; Springer, 2012; Tober and Jensen, 2013). Little bluestem possesses many desirable ornamental traits, such as variation

Received for publication 31 Oct. 2018. Accepted for publication 6 Dec. 2018.

${ }^{1}$ Corresponding author. E-mail: croback@uga.edu. in leaf color and growth habit, as well as attractive seed heads (Boe and Bortnem, 2009; Cullina, 2007; Springer, 2012).

Most ornamental grasses, like other ornamental perennial plants, are clonally propagated (Meyer et al., 2017). Often the method that growers use is division of stock plants (Meyer, 2012); however, the number of new plants is limited by the number of stock plants to be divided (Robacker and Corley, 1992). Micropropagation is a more effective method of propagation to obtain large numbers of new plants.

Micropropagation has been used to propagate ornamental grass species such as pam- pas grass and miscanthus. Shoot apices and immature inflorescences of Miscanthus $\times$ giganteus 'Freedom' were used to produce calli and regenerate shoots on Murashige and Skoog (MS) medium with 6-benzyladenine (BA) (Perera et al., 2015). Pampas grass (Cortaderia selloana Schult. 'Pumila') was propagated through tissue culture using immature inflorescences on MS medium with 2,4-Dichlorophenoxyacetic acid (2,4-D) and BA (Robacker and Corley, 1992). Chen et al. (1977) cultured big bluestem (Andropogon gerardii Vitman) from the rachis of immature inflorescences on media containing $5 \mathrm{mg} \cdot \mathrm{L}^{-1}$ 2,4-D and either with or without kinetin under dark conditions. However, Pantha et al. (2016) induced callus from mature seeds of big bluestem on MS medium combining BA and 2,4-D. Shoots were subsequently generated from the calli on MS medium with BA or kinetin (Pantha et al., 2016). Callus was induced in both big bluestem and little bluestem by culturing mature caryopses under dark conditions, so that light was excluded from the cultures, on Linsmaier and Skoog (LS) medium with kinetin and 2,4D (Li et al., 2009). Shoots were regenerated by transferring the calli to medium with kinetin; the resulting plantlets were transferred to medium with 1-Naphthaleneacetic acid (NAA) to induce root formation ( $\mathrm{Li}$ et al., 2009). Calli were produced from immature inflorescences of little bluestem cultured on revised MS (RM) medium with $1.25,2.5$, or $5.0 \mathrm{mg} \cdot \mathrm{L}^{-1}$ of either $2,4-\mathrm{D}$ or NAA and incubated in the dark (Songstad et al., 1986). Cultures initiated on the medium took $\approx 8$ weeks to produce enough callus for subculturing on the same medium. Calli were subcultured for several rounds on the initiation medium before being subcultured onto RM medium with combinations of 2,4-D and kinetin. The calli subsequently produced shoots after several rounds of subculturing on medium supplemented with kinetin. Two genotypes were subsequently incubated under light conditions on hormonefree medium for rooting (Songstad et al., 1986).

Our objective in this study was to develop an improved micropropagation protocol for little bluestem that would produce true-totype plants. To do this, we sought to minimize the time spent culturing callus, as longer times in callus can increase the chance of somaclonal variation (Neibaur et al., 2008). In addition, we used immature inflorescences as our explant, to preserve the genotype of the source plants.

Table 1. Genotypes of little bluestem used in micropropagation study according to year.

\begin{tabular}{lcc}
\hline Genotype & Location of origin for parent genotypes & Yr \\
\hline 'Good Vibrations' & Texas & 2016 \\
'Seasons in the Sun' & Texas & 2016,2017 \\
'Cinnamon Girl' & Texas & 2016 \\
B24-3 & Indiana & 2016 \\
BX10-4 & Texas and Indiana & 2016 \\
BX6-7 & Rhode Island and Texas & 2016,2017 \\
BX6-9 & Rhode Island and Texas & 2016,2017 \\
BX8-4 & Indiana and Texas & 2016,2017 \\
\hline
\end{tabular}




\section{Materials and Methods}

Plant material and disinfestation. In 2016, immature inflorescences of eight genotypes of little bluestem were harvested from plants in the field plots of the joint breeding program between the University of Georgia and the U.S. Department of Agriculture in Griffin, GA. Three genotypes were cultivars that had been released by the program, and the remaining genotypes were selections from the program that were undergoing evaluation as potential new cultivars (Table 1). In 2017, immature inflorescences of four of the genotypes that had been used the previous year were harvested (Table 1). Inflorescences were harvested prior to the flag leaf becoming horizontal and when the entire bundle of sheath leaves enclosing the inflorescence was less than 7.5 to $9.0 \mathrm{~cm}$ long. The inflorescences that were harvested were fully enclosed in sheath leaves.

Outer leaves were partially removed from the inflorescences using a scalpel and tweezers and without exposing the inflorescence itself. The inflorescences, still enclosed in sheath leaves, were then washed for $10 \mathrm{~min}$ in soapy water, rinsed in running water for 10 min, soaked for $20 \mathrm{~min}$ in a $20 \%$ solution of commercial bleach, and rinsed three times in sterile distilled water. The remaining sheath leaves were removed under sterile conditions. Inflorescences no longer than $2.5 \mathrm{~cm}$ in length were selected for culture (Fig. 1). Inflorescences were cut into pieces $\approx 5$ to $10 \mathrm{~mm}$ long to produce individual explants. Two explants were placed horizontally into each culture tube.

Culture treatments: 2016. Three light treatments were used during callus induction: full light provided by $110-\mathrm{W}$ wide-spectrum fluorescent bulbs $\left(70 \mu \mathrm{mol} \cdot \mathrm{m}^{-2} \cdot \mathrm{s}^{-1}\right)$, semilight (provided by placing the cultures in an opaque box with a translucent lid), and dark (provided by placing the cultures in a totally opaque box). Photosynthetically active radiation $(P A R)$ measurements were taken with a LI-COR LI-1500 Light Sensor Logger equipped with a LI-190 sensor (LICOR Biosciences, Inc., Lincoln, NE). Average $P A R$ measurements $\left(\mu \mathrm{mol} \cdot \mathrm{m}^{-2} \cdot \mathrm{s}^{-1}\right)$ at bench level were $54.15,18.05$, and 0.02 for full light, semilight, and dark, respectively.

Cultures were initiated on MS medium (Murashige and Skoog, 1962) and vitamins, $30.0 \mathrm{~g} \cdot \mathrm{L}^{-1}$ sucrose, and $0.75 \mathrm{~g} \cdot \mathrm{L}^{-1} \mathrm{MgCl}_{2}$. The $\mathrm{pH}$ was adjusted to 5.8 with $1 \mathrm{~N} \mathrm{NaOH}$

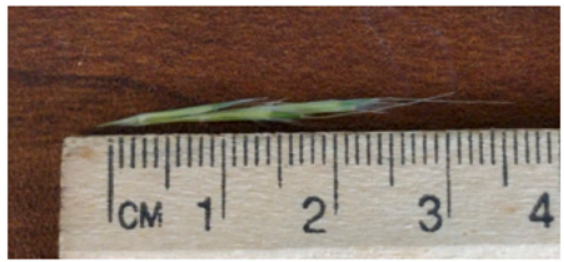

Fig. 1. Immature inflorescence of little bluestem with ruler for scale reference. Inflorescence were cut into pieces $\approx 5$ to $10 \mathrm{~mm}$ long to produce explants for culturing. and the medium was solidified with $2.0 \mathrm{~g} \cdot \mathrm{L}^{-1}$ Gelrite. Two growth regulators were added: 2,4-Dichlorophenoxyacetic acid (2,4-D) at either 0.5 or $1.0 \mathrm{mg} \cdot \mathrm{L}^{-1}$ and kinetin at either 1.0 or $2.0 \mathrm{mg} \cdot \mathrm{L}^{-1}$. The medium was dispensed in $8-\mathrm{mL}$ aliquots into $25 \times 150-\mathrm{mm}$ culture tubes capped with clear Magenta caps (Magenta, Chicago, IL) and autoclaved for $20 \mathrm{~min}$ at $121^{\circ} \mathrm{C}$. At least two explants were cultured per combination of genotype, media, and light treatment. Due to limitations of the plant material available to us and the number of factors being tested, we were not able to culture larger numbers of explants. Cultures were maintained at 27 to $30{ }^{\circ} \mathrm{C}$.

Cultures were scored $30 \mathrm{~d}$ after the initial culture date. A rating scale of 0 to 5 was used (Table 2). A score of 0 was given to cultures in which the tissue had died. Cultures with a score of 1 or higher were subcultured after being rated.

Medium for subculturing and rooting was identical to the initiation medium with the exception of the growth regulators. The effect of NAA on rooting was tested. Cultures with live tissue were initially subcultured onto medium without NAA for further growth. The culture produced from the original explant was kept intact and transferred to an individual tube. After $30 \mathrm{~d}$ on medium without NAA, half of the cultures were subcultured onto medium with $0.1 \mathrm{mg} \cdot \mathrm{L}^{-1} \mathrm{NAA}$ (Sigma Aldrich Chemical Co., St. Louis, MO) and the other half onto fresh medium without NAA. Cultures for this and subsequent subcultures were not kept intact but were broken into pieces. Cultures were subcultured every 4 to 6 weeks. Cultures that had been subcultured on medium with NAA were cycled between the medium with NAA and medium without NAA until rooted. The remaining cultures were subcultured onto medium without NAA until rooted.

All pieces of cultures in a tube were placed onto fresh media during subculturing. Any rooted plants were separated from unrooted cultures and placed in tubes with fresh media with no growth regulator to await transplantation. Cultures were initiated in

Table 2. Rating system for scoring of initial cultures of little bluestem after $30 \mathrm{~d}$.

\begin{tabular}{ll}
\hline Score & \multicolumn{1}{c}{ Criteria } \\
\hline 0 & Explant died \\
1 & At least some callus formed, but little or no growth occurred \\
2 & Tissue exhibited some callus growth, but no more than 1 leaf or shoot had formed \\
3 & Tissues had doubled in size, and leaves, shoot buds, or shoots were present \\
4 & Tissues had tripled or quadrupled in size and consisted mostly of shoot buds and/or shoots \\
5 & Surface of the medium was covered with shoot buds and/or shoots \\
\hline
\end{tabular}
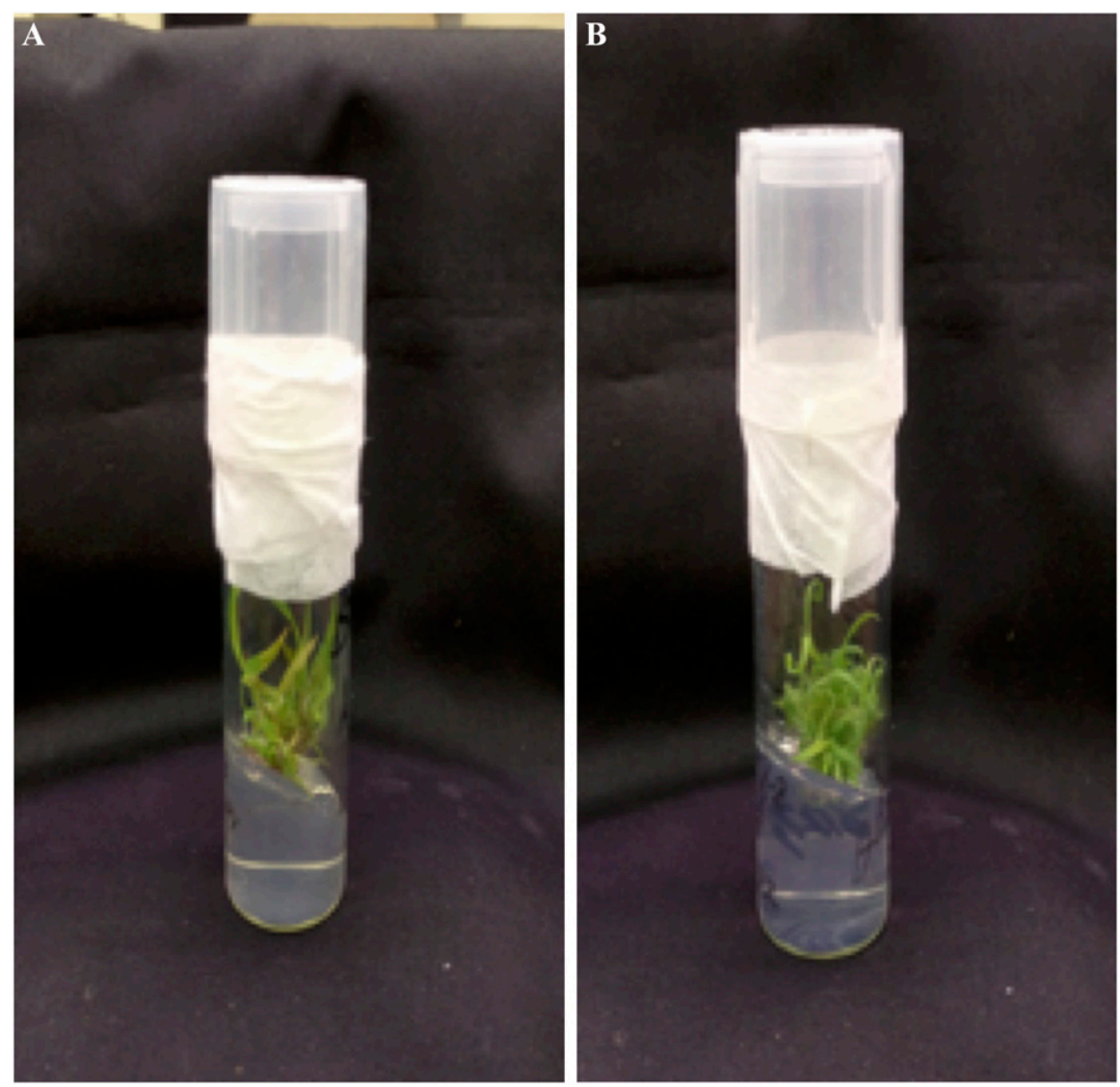

Fig. 2. Little bluestem cultures several weeks after scoring (A) and during shoot and root formation (B). 
July and August and were subcultured until Jan. 2017.

Culture treatments: 2017. In 2017, all cultures were initiated under $110-\mathrm{W}$ widespectrum fluorescent lights.

Initiation media and culture conditions were similar to those used in 2016 except for growth regulators. In 2017, the initiation medium included $0.5 \mathrm{mg} \cdot \mathrm{L}^{-1}$ of $2,4-\mathrm{D}$ and either $1.0 \mathrm{mg} \cdot \mathrm{L}^{-1}$ kinetin or $1.0 \mathrm{mg} \cdot \mathrm{L}^{-1} 6$ benzylaminopurine (BAP). At least 60 explants were cultured per combination of genotype and media treatment. Cultures were scored $30 \mathrm{~d}$ after the initial culture date according to the scale in Table 2. Medium for subculturing and rooting was identical to the initiation medium with the exception of the growth regulators.

Cultures with live tissue were subcultured onto medium with either $1.0 \mathrm{mg} \cdot \mathrm{L}^{-1} \mathrm{BAP}$ or $1.0 \mathrm{mg} \cdot \mathrm{L}^{-1}$ kinetin for further growth. Cultures were initially subcultured onto medium with the same cytokinin as the medium on which they had been initiated. As in 2016, the culture produced from the original explant was kept intact and transferred to an individual tube. In 2017, each original explant was assigned an individual number after the initial subculture, to track the rate of rooting. Cultures were subcultured every 4 to 6 weeks (Fig. 2). Cultures were broken into pieces after the initial subculture and at every subculture tubes were labeled with the number given to the initial explant. From the second subculture on, cultures were cycled between medium containing cytokinin and medium with no cytokinin until rooted. All pieces of cultures in a tube were placed onto fresh media during subculturing. Cultures were

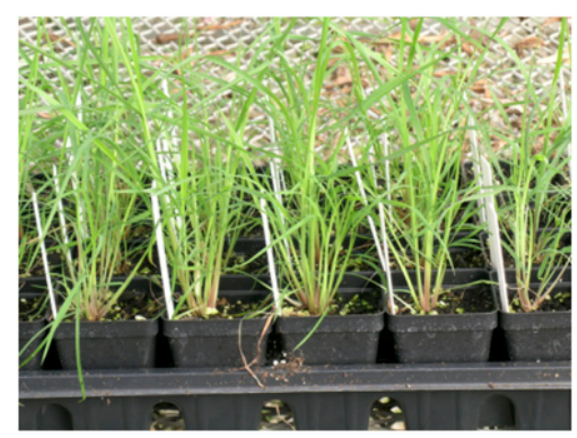

Fig. 3. Little bluestem plants produced through micropropagation initiated in July and August and were subcultured until Feb. 2018.

Transplantation and acclimatization. Plants were considered rooted when they had at least one root that was at least $1 \mathrm{~cm}$ in length. Number of days to rooting was measured as the number of days between initial culture date and the day the plant was transplanted to the greenhouse. Rooted plants were transferred to Sungro Professional Growing Mix (Sungro Professional Growing Mix; Sun Gro Horticulture, Agawam, MA) and acclimated under intermittent mist (10 s every $30 \mathrm{~min}$ ) with no shade in the greenhouse for 2 to 3 weeks. Plants were maintained in the greenhouse once they had acclimated (Fig. 3).

Data analysis. A completely randomized design was used for both the 2016 and 2017 experiments. Data were analyzed in SAS 9.3 (SAS Institute, Inc., Cary, NC) using proc glimmix. Means separation was performed using Tukey's honestly significant difference $(P<0.05)$ for differences within treatment method. Analyses for individual factors, such as initiation media or genotype, were done over all treatment combinations unless otherwise noted. Each explant was considered one replicate.

\section{Results and Discussion}

2016 experiment. Initial light conditions had no effect on cultures in 2016 (data not shown). Although the scores of cultures rated $30 \mathrm{~d}$ after the initial culture date under light and semilight conditions were higher than those under dark conditions, the differences were not significant $(P=0.1360)$. Initial light treatment also had no effect on days to rooting $(P=0.7914)$ or on the number of rooted plants obtained per initial culture $(P=$ 0.3222).

Previous studies of micropropagation of little bluestem have incubated cultures in the dark to produce callus (Chen and Boe, 1988; Li et al., 2009; Songstad et al., 1986). Cultures in the Songstad et al. (1986) study were also incubated in the dark to produce shoots. However, our study shows that incubation in the dark is not necessary to produce either callus or shoots.

Initiation media made a clear difference in scores of cultures rated $30 \mathrm{~d}$ after the initial culture date. Cultures on initiation media with kinetin at $1.0 \mathrm{mg} \cdot \mathrm{L}^{-1}$ and either 0.5 or
$1.0 \mathrm{mg} \cdot \mathrm{L}^{-1}$ 2,4-D had higher scores and initiated callus at twice the rate than cultures on kinetin at $2.0 \mathrm{mg} \cdot \mathrm{L}^{-1}$ and either level of 2,4-D $(P=0.0002)$ (Table 3$)$. The results we obtained using 2,4-D are contrary to the study of micropropagation of little bluestem by Songstad et al. (1986), who found that callus production was highest on medium with the highest concentration, $5 \mathrm{mg} \cdot \mathrm{L}^{-1}$, of 2,4-D. However, explants later transferred to medium with $0.1 \mathrm{mg} \cdot \mathrm{L}^{-1}$ of $2,4-\mathrm{D}$ produced fewer shoots than medium without 2,4-D (Songstad et al., 1986). Our results are also different from those of the study by Li et al. (2009) of micropropagation of mature caryopses of little bluestem. In that study, higher amounts of 2,4-D in the initiation media produced larger amounts of callus, especially when combined with kinetin (Li et al., 2009). The amount of 2,4-D also may have an effect on the rate at which callus is produced. In the study by Songstad et al. (1986), explants cultured on higher amounts of 2,4-D took 8 weeks to produce enough callus to subculture (Songstad et al., 1986), whereas in our study we were able to produce callus after 4 weeks using lower amounts of 2,4-D combined with another growth regulator. As well, higher amounts of 2,4-D in the initiation medium could possibly lead to a higher possibility of somaclonal variation.

Our results using different concentrations of kinetin in initiation media are different from those of the study of micropropagation of little bluestem by Li et al. (2009) that showed no real difference in the amount of callus produced on initiation media with different amounts of kinetin. This is also contrary to results from the Songstad et al. (1986) study, which found that cultures transferred to media containing 2,4-D and higher amounts of kinetin produced more shoots. Our study shows that increased amounts of kinetin in initiation media are not necessary to produce callus and shoots.

The number of rooted plants obtained per initial culture was different among initiation media over all initial light conditions, subculture media, and genotypes $(P=0.0410)$ (Table 3). Cultures initiated on either of the media containing $1.0 \mathrm{mg} \cdot \mathrm{L}^{-1}$ kinetin produced almost twice the number of rooted plants than media with $1.0 \mathrm{mg} \cdot \mathrm{L}^{-1} 2,4-\mathrm{D}$ and $2.0 \mathrm{mg} \cdot \mathrm{L}^{-1}$ kinetin. In addition, initiation media significantly affected the number of days to rooting $(P=0.0065)$ from the initial

Table 3. Scores of little bluestem cultures on initiation media rated $30 \mathrm{~d}$ after initial culture date, number of plants rooted per explant, and days to rooting.

\begin{tabular}{|c|c|c|c|c|c|c|c|c|}
\hline & & \multirow[b]{2}{*}{$2,4-\mathrm{D}(\mathrm{mg} / \mathrm{L})$} & \multicolumn{3}{|c|}{2016} & \multicolumn{3}{|c|}{2017} \\
\hline & & & $\begin{array}{c}\text { Scores } 30 \mathrm{~d} \\
\text { after initial culture }\end{array}$ & $\begin{array}{l}\text { Number rooted } \\
\text { per initial culture }\end{array}$ & $\begin{array}{l}\text { Days to rooting } \\
\text { from initial culture date }\end{array}$ & $\begin{array}{l}\text { Scores } 30 \mathrm{~d} \text { after } \\
\text { initial culture }\end{array}$ & $\begin{array}{c}\text { Number rooted } \\
\text { per explant cultured }\end{array}$ & $\begin{array}{l}\text { Days to rooting } \\
\text { from initial } \\
\text { culture date }\end{array}$ \\
\hline \multirow[t]{4}{*}{$\overline{\text { Kinetin }(\mathrm{mg} / \mathrm{L})}$} & 1.0 & 0.5 & $1.68 \pm 0.14 \mathrm{a}$ & $6.89 \pm 1.23 \mathrm{a}$ & $122.01 \pm 2.90 \mathrm{a}$ & $0.34 \pm 0.06 \mathrm{~b}$ & $14.37 \pm 3.09 \mathrm{~b}$ & $161.01 \pm 2.62 b$ \\
\hline & & 1.0 & $1.43 \pm 0.15 \mathrm{a}$ & $7.43 \pm 1.09 \mathrm{a}$ & $109.74 \pm 2.68 b$ & - & - & - \\
\hline & 2.0 & 0.5 & $0.81 \pm 0.18 b$ & $4.41 \pm 1.30 \mathrm{ab}$ & $111.67 \pm 3.29 b$ & - & - & - \\
\hline & & 1.0 & $0.93 \pm 0.16 b$ & $3.52 \pm 0.97 b$ & $110.27 \pm 3.43 b$ & - & - & - \\
\hline $\operatorname{BAP}(\mathrm{mg} / \mathrm{L})$ & 1.0 & 0.5 & - & - & - & $0.96 \pm 0.06 \mathrm{a}$ & $33.32 \pm 3.79 \mathrm{a}$ & $199.75 \pm 2.45 \mathrm{a}$ \\
\hline
\end{tabular}

Values represent means \pm sE. Means within a column followed by different letters are significantly different at $P<0.05$. Dash indicates that the treatment combination was not used for the year listed. Only one level of 2,4-D was used in 2017. 
culture date (Table 3), although cultures on all initiation and subculture media produced rooted plants in 110 to $122 \mathrm{~d}$.

Genotype made a clear difference in the scores of cultures rated $30 \mathrm{~d}$ after the initial culture date ( $P=0.0187$, Table 4$)$. In 2016, 'Good Vibrations', 'Seasons in the Sun', BX6-7 and BX8-4 had the highest scores. The number of rooted plants obtained per explant placed on subculture media was also different among genotypes $(P=0.0187)$ (Table 4). Genotype BX6-9 produced the highest number of rooted plants averaged over initiation media, initial light conditions, and subculture media. Due to mortality of some cultures, genotype B24-3 was not fully replicated across all treatments, so it was removed from the analysis. Genotype also had an effect on days to rooting from initial culture date $(P<0.0001)$ (Table 4$)$. Genotype BX6-9, at $101 \mathrm{~d}$, was quickest to root. In contrast, 'Cinnamon Girl' and BX8-4 took $126 \mathrm{~d}$ to root from the initial culture.

Genotype has previously been shown to have an effect on micropropagation of grasses. In a study of micropropagation of three genotypes of little bluestem, one genotype had almost three times the number of shoots than another genotype (Songstad et al., 1986). Genotype had a significant effect on the number of shoots regenerated in the micropropagation of 'Bison' and 'Bonilla' big bluestems, with 'Bonilla' producing almost twice as many shoots on the same media (Li et al., 2009). The percentage of callus induction of four genotypes of Miscanthus lutarioriparius L. Liou ex Renvoize \& S. L. Chen ranged from 95\% for two genotypes down to $15 \%$ for one genotype on identical media (Zhao et al., 2016).

NAA in subculture medium significantly affected the number of days to rooting from initial culture $(P=0.0006)$ (Table 5). Plants on media without NAA produced rooted plants $12 \mathrm{~d}$ before plants on media with 0.1 $\mathrm{mg} \cdot \mathrm{L}^{-1}$ NAA. However, NAA made no difference in the number of rooted plants obtained across all genotypes $(P=0.1081)$ (Table 5). Cultures subcultured on medium containing NAA produced an average of 1.5 plants per culture placed on rooting medium, whereas cultures subcultured on medium with no NAA produced an average of 2.2 plants over all genotypes, initial light treatments, and initiation media.

The addition of up to $0.5 \mathrm{mg} \cdot \mathrm{L}^{-1} \mathrm{NAA}$ had no effect on the rate of rooting of little bluestem cultures in a study by $\mathrm{Li}$ et al. (2009). In addition, in that study, cultures rooted on media with $1.0 \mathrm{mg} \cdot \mathrm{L}^{-1}$ or higher NAA produced significantly fewer roots. Pantha et al. (2016) reported a $90 \%$ rate of rooting on media with no additional hormones for big bluestem cultures. However, cultures of Miscanthus sinensis had higher percentages of rooting on media supplemented with $0.2 \mathrm{mg} \cdot \mathrm{L}^{-1} \mathrm{NAA}$ than on media with no additional NAA, although higher concentrations of NAA had a deleterious effect on rooting (Zhang et al., 2012). The value of NAA as an addition to media to promote rooting may be species dependent.

Mortality of plants rooted and transplanted to the greenhouse was $6.0 \%$. Evaluation of plants in the greenhouse and in the field showed no morphological differences.

2017 experiment. We used full-light conditions for all cultures from initiation to rooting. As the concentration of 2,4-D had no effect in 2016 , only $0.5 \mathrm{mg} \cdot \mathrm{L}^{-1} 2,4-\mathrm{D}$ was used in initiation media in 2017. Furthermore, because initiation media with 1.0 $\mathrm{mg} \cdot \mathrm{L}^{-1}$ kinetin produced more callus and shoots in 2016 than initiation media with $2.0 \mathrm{mg} \cdot \mathrm{L}^{-1}$ kinetin, in 2017 we used the lower amount of kinetin in initiation media to compare with initiation media containing BAP. Adding NAA to subculture media in 2016 did not result in a greater number of rooted plants, and explants on subculture media with NAA produced roots more slowly. Therefore, NAA was not added to subculture media in 2017.

Scores of cultures rated $30 \mathrm{~d}$ after the initial culture date were different between initiation media. Cultures on medium with $1.0 \mathrm{mg} \cdot \mathrm{L}^{-1}$ BAP had higher scores and initiated two to three times more callus than cultures on medium with $1.0 \mathrm{mg} \cdot \mathrm{L}^{-1}$ kinetin $(P<0.0001)$ (Table 3$)$. The number of rooted plants obtained per explant cultured was approximately twice as much on media with BAP than on media with kinetin over all genotypes $(P=0.0004)$ (Table 3$)$ with BAP having a more than 2-fold increase in number rooted per explant. Explants cultured on initiation and subculture media containing BAP produced more rooted plants than those cultured on initiation and subculture media containing kinetin.

Cytokinins are effective at stimulating shoot initiation in tissue culture (Thomas et al., 1996). Both BA and kinetin have been used as effective components in the micropropagation of grasses. Media supplemented with BA was more successful than media without BA in micropropagation of creeping bluestem [Schizachyrium scoparium (Michx.) Nash var. stoloniferum (Nash) J. Wipff] (Chakravarty et al., 2001). When a moderate amount of BA was added to media with 2,4-D in the micropropagation of Miscanthus sinensis Andersson, higher amounts of embryonic callus were produced (Zhang et al., 2012). Callus cultures of bermudagrass had enhanced ability to regenerate shoots when BA was added to media containing 2,4-D (Chaudhury and $\mathrm{Qu}, 2000)$; however, kinetin was more successful than BA in regenerating shoots during micropropagation of big bluestem (Pantha et al., 2016). Shoot regeneration was improved and shoot count increased with the addition of kinetin to media in other studies of micropropagation of little bluestem ( $\mathrm{Li}$ et al., 2009; Songstad et al., 1986). To our knowledge, no other studies of micropropagation of little bluestem have compared the effects of incorporating BA vs. kinetin into the media. In our study, although kinetin was an effective component of media for micropropagation of little bluestem, it was not as effective as BAP.

Initiation and subculture media also affected the number of days to produce rooted plants $(P<0.0001)$ (Table 3). Cultures initiated and subcultured on medium with kinetin produced rooted plants more quickly than those on medium with BAP; however, cultures on all initiation and subculture media produced rooted plants in 181 to $196 \mathrm{~d}$.

Genotype made a clear difference in the scores of cultures rated $30 \mathrm{~d}$ after the initial culture date $(P<0.0001)$ (Table 4$)$. Genotypes BX6-7 and BX8-4 had the highest scores. A difference was also found among

Table 4. Effect of genotype on scores of little bluestem cultures rated $30 \mathrm{~d}$ after initial culture date, number of plants rooted per initial explant placed on subculture media, and days to rooting.

\begin{tabular}{|c|c|c|c|c|c|c|}
\hline \multirow[b]{2}{*}{ Genotype } & \multicolumn{3}{|c|}{2016} & \multicolumn{3}{|c|}{2017} \\
\hline & $\begin{array}{l}\text { Scores } 30 \mathrm{~d} \text { after } \\
\text { initial culture }\end{array}$ & $\begin{array}{c}\text { Number rooted } \\
\text { per initial explant } \\
\text { subcultured }\end{array}$ & $\begin{array}{l}\text { Days to rooting } \\
\text { from initial } \\
\text { culture date }\end{array}$ & $\begin{array}{l}\text { Scores } 30 \mathrm{~d} \\
\text { after initial culture }\end{array}$ & $\begin{array}{c}\text { Number rooted } \\
\text { per initial explant } \\
\text { subcultured }\end{array}$ & $\begin{array}{l}\text { Days to rooting from } \\
\text { initial culture date }\end{array}$ \\
\hline 'Cinnamon Girl' & $0.99 \pm 0.22 \mathrm{bc}$ & $5.19 \pm 1.44 \mathrm{~b}$ & $125.59 \pm 4.21 \mathrm{a}$ & - & - & - \\
\hline 'Good Vibrations' & $1.68 \pm 0.20 \mathrm{a}$ & $3.94 \pm 1.14 b$ & $105.08 \pm 3.05 b$ & - & - & - \\
\hline 'Seasons in the Sun' & $1.36 \pm 0.17 \mathrm{ab}$ & $4.11 \pm 1.14 \mathrm{~b}$ & $116.62 \pm 3.09 \mathrm{a}$ & $0.30 \pm 0.07 \mathrm{~b}$ & $16.47 \pm 4.08 \mathrm{~b}$ & $196.61 \pm 8.93 \mathrm{a}$ \\
\hline $\mathrm{B} 24-3^{\mathrm{z}}$ & $0.88 \pm 0.33 \mathrm{bc}$ & - & $115.96 \pm 4.30 \mathrm{a}$ & - & - & - \\
\hline BX10-4 & $0.52 \pm 0.28 \mathrm{c}$ & $2.84 \pm 2.45 b$ & $106.35 \pm 8.62 \mathrm{ab}$ & - & - & - \\
\hline BX6-7 & $1.13 \pm 0.24 \mathrm{abc}$ & $3.40 \pm 1.70 \mathrm{~b}$ & $112.17 \pm 4.03 \mathrm{ab}$ & $1.05 \pm 0.07 \mathrm{a}$ & $41.71 \pm 6.15 \mathrm{a}$ & $181.36 \pm 3.04 \mathrm{a}$ \\
\hline BX6-9 & $0.88 \pm 0.31 \mathrm{bc}$ & $14.09 \pm 2.20 \mathrm{a}$ & $101.24 \pm 4.37 \mathrm{~b}$ & $0.31 \pm 0.08 \mathrm{~b}$ & $48.93 \pm 13.88 \mathrm{a}$ & $189.09 \pm 5.08 \mathrm{a}$ \\
\hline BX8-4 & $1.77 \pm 0.25 \mathrm{a}$ & $5.36 \pm 1.14 \mathrm{~b}$ & $126.12 \pm 3.97 \mathrm{a}$ & $0.88 \pm 0.07 \mathrm{a}$ & $22.60 \pm 3.70 \mathrm{~b}$ & $186.85 \pm 3.54 \mathrm{a}$ \\
\hline
\end{tabular}

Values represent means \pm SE. Means within a column followed by different letters are significantly different at $P<0.05$.

${ }^{\mathrm{z}}$ Genotype B24-3 was removed from the analysis of number rooted per culture scored and placed on rooting media because rooted plants of this genotype were not fully replicated across each combination of initiation media, initial light treatment, and rooting media. 
Table 5. Effect of subculture media on number of days to rooting of little bluestem cultures in 2016.

\begin{tabular}{llc}
\hline Subculture medium & Days to rooting & Number rooted \\
\hline Without NAA & $110.31 \pm 1.89 \mathrm{~b}$ & $2.22 \pm 0.31 \mathrm{a}$ \\
$0.1 \mathrm{mg} \cdot \mathrm{L}^{-1}$ NAA & $122.66 \pm 3.08 \mathrm{a}$ & $1.55 \pm 0.26 \mathrm{a}$ \\
\hline
\end{tabular}

Values represent means \pm SE. Means within a column followed by different letters are significantly different at $P<0.05$. Number rooted by subculture media calculated over all genotypes.

genotypes in the number of rooted plants obtained per explant placed on subculture media $(P=0.0012)$ (Table 4). Explants of genotypes BX6-7 and BX6-9 produced more rooted plants than explants of genotypes 'Seasons in the Sun' and BX8-4. However, genotype had no effect on the number of days to rooting across all initiation and subculture media $(P=0.2530)$ (Table 4$)$. All genotypes rooted in 181 to $197 \mathrm{~d}$.

Mortality of plants rooted and transplanted to the greenhouse was $6.3 \%$ in 2017. Only two plants of 1590 transplanted showed morphological differences in 2017. Leaves of the two plants with morphological differences were more yellow and thicker than those of the parent plant. All other little bluestem plants produced by micropropagation grew true-to-type.

Comparing 2016 with 2017. A comparison of scores $30 \mathrm{~d}$ after initiation across all genotypes and media in 2016 vs. 2017 revealed that scores were higher in 2016 (Table 3). The higher percentage of cultures with a score of 0 (dead tissue) in 2017 than in 2016 lowered the average score of cultures initiated in 2017. In 2016, 38.8\% of cultures initiated were given a score of 0 , whereas in 2017 a score of 0 was given to $58.8 \%$ of cultures initiated. In 2017, three of the four genotypes in the study, 'Seasons in the Sun', BX6-7, and BX8-4, bloomed later than in 2016 (7, 9, and $15 \mathrm{~d}$, respectively). For all genotypes in 2017, inflorescences were slower to develop to the optimal stage for culturing after plants were in bloom (personal observation). Environmental conditions were different between 2016 and 2017 in the periods during which inflorescences were developing and cultures were initiated (June through the middle of August). Daytime temperatures in 2017 averaged $3.1{ }^{\circ} \mathrm{C}$ cooler and rainfall was $125 \mathrm{~mm}$ higher than in 2016 (www.weather.net, Griffin-Dempsey Farm, accessed 9 July 2018). Cooler, wetter conditions in the field may have been suboptimal for inflorescence development and the ability of the inflorescences to generate callus when cultured.

Genotypes BX6-7 and BX8-4 had high scores $30 \mathrm{~d}$ after culture initiation in both years, although BX6-9 produced the most rooted plants. Number of rooted plants obtained for each genotype was greater in 2017 (Table 4). The use of subculture media with cytokinins was more effective at inducing shoot proliferation, which led to an increase in rooted plants over 2016. However, days to rooting from culture initiation was higher in 2017 (Table 4), likely reflecting the amount of time cultures spent in shoot proliferation before rooting.

\section{Conclusion}

Our study provides a protocol for the rapid regeneration of little bluestem through micropropagation of immature inflorescences. We were able to produce large numbers of rooted plants that established easily in the greenhouse and grew true-totype. Our recommendation is to use initiation media consisting of MS salts and vitamins with $1.0 \mathrm{mg} \cdot \mathrm{L}^{-1} \mathrm{BAP}$ and $0.5 \mathrm{mg} \cdot \mathrm{L}^{-1} 2,4-\mathrm{D}$. Cultures should be initiated and subcultured under light. Once callus has formed, cultures should be transferred to subculture medium and subcultured every 30 to $45 \mathrm{~d}$. Subculture medium should consist of MS media containing $1.0 \mathrm{mg} \cdot \mathrm{L}^{-1} \mathrm{BAP}$ and without $2,4-\mathrm{D}$. Once shoots have formed, continue to subculture on subculture medium alternating with medium containing no additional growth regulators every 30 to $45 \mathrm{~d}$ until roots form. The rooted plants may then be transplanted and acclimated in a greenhouse under intermittent mist. Our regeneration system should prove helpful to propagators and researchers.

\section{Literature Cited}

Boe, A. and R. Bortnem. 2009. Morphology and genetics of biomass in little bluestem. Crop Sci. 49:411-418

Chakravarty, T., J.G. Norcini, J.H. Aldrich, and R.S. Kalmbacher. 2001. Plant regeneration of creeping bluestem (Schizachyrium scoparium (Michx.) Nash var. stoloniferum (Nash) J. Wipff) via somatic embryogenesis. In Vitro Cell. Dev. Biol. Plant 37:550-554.

Chaudhury, A. and R. Qu. 2000. Somatic embryogenesis and plant regeneration of turf-type bermudagrass: Effect of 6-benzyladenine in callus induction medium. Plant Cell Tissue Organ Cult. 60:113-120.

Chen, C.H. and A.A. Boe. 1988. Big bluestem (Andropogon gerardii Vitman), little bluestem (Schizachyrium scoparium (Michx.) Nash), and Indiangrass (Sorghastrum nutans (1.) Nash), $\mathrm{p}$. 444-457. In: Y.P.S. Bajaj (ed.). Biotechnology in agriculture and forestry 6 . Crops II. SpringerVerlag, Berlin, Germany.

Chen, C.H., N.E. Stenberg, and J.G. Ross. 1977 Clonal propagation of big bluestem by tissue culture. Crop Sci. 17:847-850.

Cullina, W. 2007. Schizachyrium scoparium (little bluestem). Horticulture 104:A8.

Fu, Y.-B., A.T. Phan, B. Coulman, and K.W. Richards. 2004. Genetic diversity in natural populations and corresponding seed collections of little bluestem as revealed by AFLP markers. Crop Sci. 44:2254-2260.
Li, Y., J. Gao, and S. Fei. 2009. High frequency embryogenic callus induction and plant regeneration from mature caryposis of big bluestem and little bluestem. Scientia Hort. 121:348352.

Meyer, M.H. 2012. Ornamental grasses in the United States. Hort. Rev. 39:121-152.

Meyer, M.H., B. Fair, J.E. Klett, J. Rozum, K. Moore, H.B. Pemberton, L. Perry, A. Shay, and M.D. Taylor. 2017. Switchgrass and little bluestem cultivars show performance variation across eight states in national grass trials. HortTechnology 27:731-738.

Murashige, T. and F. Skoog. 1962. A revised medium for rapid growth and bio assays with tobacco tissue cultures. Physiol. Plant. 15:473497.

Neibaur, I., M. Gallo, and F. Altpeter. 2008. The effect of auxin type and cytokinin concentration on callus induction and plant regeneration frequency from immature inflorescence segments of seashore paspalum (Paspalum vaginatum Swartz). In Vitro Cell. Dev. Biol. Plant 44:480-486.

Pantha, P., S.K. Ponniah, S. Ntamatungiro, and M. Manoharan. 2016. Improved embryogenic callus induction and plant regeneration in big bluestem (Andropogon gerardii Vitman), a potential bioenergy feedstock. Afr. J. Biotechnol. 15:2166-2171.

Perera, D., D. Barnes, B. Baldwin, and N. Reichert. 2015. Direct and indirect in vitro regeneration of Miscanthus $\times$ giganteus cultivar Freedom: Effects of explant type and medium on regeneration efficiency. In Vitro Cell. Dev. Biol. Plant 51:294-302.

Robacker, C.D. and W.L. Corley. 1992. Plant regeneration of pampas grass from immature inflorescences cultured in vitro. HortScience 27:841-843.

Songstad, D.D., C.H. Chen, and A.A. Boe. 1986. Plant regeneration in callus cultures derived from young inflorescences of little bluestem. Crop Sci. 26:827-829.

Springer, T. 2012. Variation for canopy morphology in little bluestem. Crop Sci. 52:729737.

Thomas, G., K. Claire, P. Claude, G. Hubert, M.R. David, and A.T. Trevor. 1996. Plant hormones and plant growth regulators in plant tissue culture. In Vitro Cell. Dev. Biol. Plant 32: 272-289.

Tober, D. and N. Jensen. 2013. Plant guide for little bluestem (Schizachyrium scoparium). USDA Natural Resources Conservation Service, Plant Materials Center, Bismarck, ND.

U.S. Department of Agriculture. 2014. Quick stats. 17 Jan. 2018. <https://quickstats.nass.usda. gov>.

Williams, D.G. and D.D. Briske. 1991. Size and ecological significance of the physiological individual in the bunchgrass Schizachyrium scoparium. Oikos 62:41-47.

Zhang, Q.X., Y. Sun, H.K. Hu, B. Chen, C.T. Hong, H.P. Guo, Y.H. Pan, and B.S. Zheng. 2012. Micropropagation and plant regeneration from embryogenic callus of Miscanthus sinensis. In Vitro Cell. Dev. Biol. Plant 48:50 57.

Zhao, L., Y. Diao, S. Jin, F. Zhou, and Z. Hu. 2016. Effect of genotype and inflorescence developmental stage on callus induction and plant regeneration of Miscanthus lutarioriparius, a non-food biomass crop. Pak. J. Bot. 48:717722 . 